Membership of the association includes students to retired consultants and we organise regular meetings mainly on arts subjects. In 1985 we ventured on our first exhibition of paintings, drawings, sculptures, photographs, etc, most of which had never been on show in public before. All contributors found it inspiring to share and discuss their experiences with others and at present we are organising our next exhibition, which will go on show in different parts of Denmark.

We also realised that there are many talented musicians in our profession and regularly include a musical session in our meetings. Recently some of them gathered in the beautiful setting of the Copenhagen Renoir collection (Ordrupgaardsamlingen), where they performed music composed by five other members. In the future we will cover other aspects such as poetry and architecture and we plan to run courses in, for example, drawing and painting.
Our association has been an inspiration for those concerned as both a recreational pastime and a rewarding extension to our professional lives. We are still in the process of developing our ideas and would very much like to contact similar organisations abroad. Otherwise we hope that our experience will inspire others to form associations with which we can arrange future exhibitions and concerts.

I thank Astra-Gruppen A/S for providing the negatives to the photographs.

Department of Internal Medicine C, Bispebjerg Hospital, Bispebjerg Bakke 23, 2400 Copenhagen, Denmark

HANS PERRILD, MD, senior registrar

\title{
Babies, bottles, and boobs
}

\section{CLOSE}

In tropical developing countries great emphasis is placed on the advantages of breast milk over non-breast milk substitutes. This gospel is spread by professionals in the health services and the media-especially local radio and newspaper articles-and is often official government policy with restrictions on the sale and promotion of infant formulae. You would therefore expect children in the West Indies to be aware of breast feeding as the natural choice. And because of the léss obvious promotion and education about breast feeding in the United Kingdom, especially by the media, you would expect children to consider bottle feeding of infants natural.

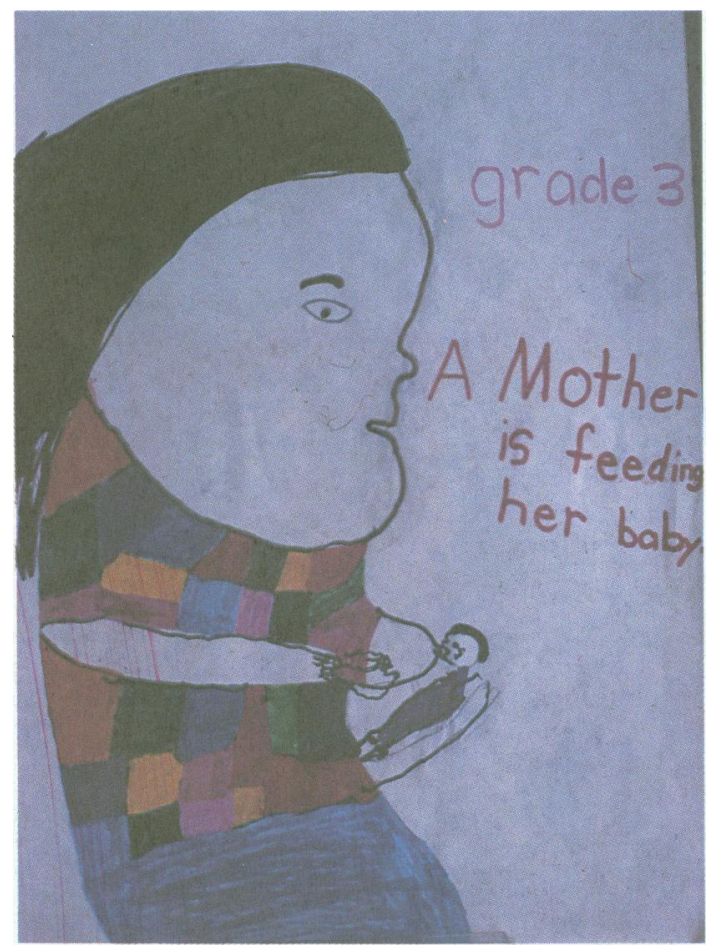

Breast feeding drawn by an 8 year old West Indian girl.



Breast feeding drawn by a 7 year old Redditch boy.

Subjects, methods, and results

School children living on the island of Dominica in the eastern Caribbean and children attending school in Redditch, England, were included in the study. The class teacher instructed them to draw a picture of a mother feeding her young infant. Eighty six West Indian children and 184 English children completed a picture. Ages ranged from 6 to 10 years. Analysis of the results in each cultural group showed no important differences between different age groups in the numbers showing breast feeding as opposed to bottle feeding. There was also no difference between the type of feeding drawn by boys and girls. Comparing the two cultural groups, 




Bottle feeding in a middle class West Indian home.

however, there was a difference with the West Indian children drawing the greater number of breast feeding mothers as shown in the table.

Differences between West Indian and English children depicting a mother feeding her infant

\begin{tabular}{lcc}
\hline & $\begin{array}{c}\text { Breast feeders } \\
\text { No (\%) }\end{array}$ & $\begin{array}{c}\text { Bottle or spoon feeders } \\
\text { No (\%) }\end{array}$ \\
\hline $\begin{array}{l}\text { West Indies } \\
\text { England }\end{array}$ & $73(85)$ & $13(15)$ \\
& $39(21)$ & $145(79)$ \\
\hline
\end{tabular}

Breast feeding was usually shown as an intimate activity with close contact between the mother and child. Bottle feeders, especially in the West Indies, often took place in middle class homes as shown by the display of hi-fi equipment and electric fans, etc. Bottle feeding was often portrayed as an activity to be done at arm's length and often caused distress to the baby. One child showed great



Bottle feeding at arm's length. ingenuity and drew a picture of a baby within its mother and this is the only example of placental feeding in the study. The drawing, however, is fairly incomprehensible and has been likened to an ultrasound scan from the antenatal clinic. I am waiting for my radiology colleague to report on this drawing.

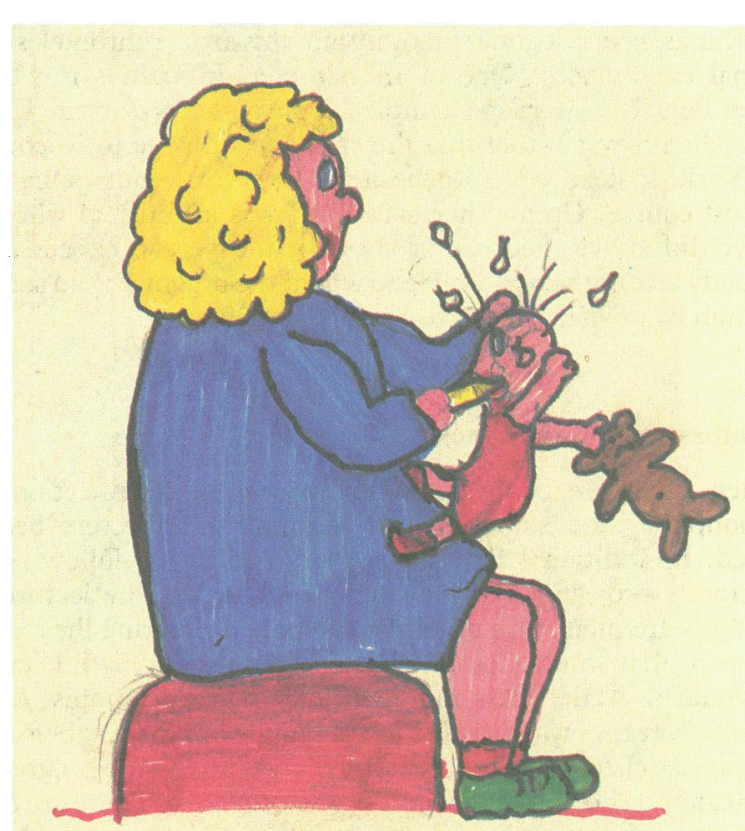

Bottle feeding may be stressful, drawn by a Redditch child.

\section{Comment}

Dominica can claim that the percentage of infants receiving breast milk is $94 \%$ for those under 6 months of age, $70 \%$ between 6 and 12 months, and $18 \%$ beyond 1 year. Exclusive breast feeding continues for a mean of three months and in a survey of 319 mothers only one had not breast fed her infant.' So called developed countries cannot compete with these figures and never will until our children are exposed to the idea that breast feeding is the natural method of infant feeding. This message needs to be given by many sources that influence children's development of ideas and concepts. These include the family, the school, books, magazines, newspapers, television, and films. We need to get away from the idea that breasts are for the entertainment of dad on page 3 of his daily newspaper. We need to get away from the need to screen off breast feeding mothers behind curtains on the postnatal wards as if they were doing something unnatural (though, because of their cultural upbringing the mothers probably wish to be screened off). Breast feeding needs to be brought into the open. For this reason I would advise midwives on postnatal wards to draw the screens around bottle feeders.

\section{Reference}

1 Close GC, van den Hazel P. Nutritional status of young children in Dominica. West Indies Medical Joumal 1986;35:103-5.

Redditch, Worcs B97 4DJ

C CLOSE, DCH, MRCP, consultant community paediatrician

Correspondence to: Smallwood Health Centre, Church Green West, Redditch, Worcs B97 4DJ. 